\title{
Biologia e ecofisiologia de buva (Conyza bonariensis e Conyza canadensis)
}

\author{
Biology and ecophysiology of hairy fleabane (Conyza bonariensis) and horseweed (Conyza canadensis)
}

\author{
Carlos Alberto Lazaroto ${ }^{\mathrm{I}}$ Nilson Gilberto Fleck ${ }^{\mathrm{II}}$ Ribas Antonio Vidal ${ }^{\mathrm{II}}$
}

\section{- REVISÃO BIBLIOGRÁFICA -}

\section{RESUMO}

Conyza bonariensis (L.) Cronquist e Conyza canadensis (L.) Cronquist são duas espécies de plantas daninhas pertencentes à família Asteraceae. Com freqüência, elas infestam pomares, vinhedos e outras culturas, como milho, soja e algodão e, também, culturas forrageiras, pastagens e áreas não-cultivadas. Esta revisão de literatura tem por objetivos descrever e discutir as características botânicas, biológicas e ecofisiológicas daquelas espécies com a finalidade de facilitar a adoção de estratégias para seu manejo em culturas ou limitar seu estabelecimento. Conyza canadensis é uma espécie anual ou bienal, nativa da América do Norte, enquanto C. bonariensis é uma espécie anual, nativa da América do Sul. A propagação destas espécies dá-se através de sementes que são facilmente dispersas através do vento e da água. As sementes não apresentam dormência e podem germinar prontamente em condições de temperatura e umidade favoráveis. Em vários países, inclusive no Brasil, foi constatada resistência aos herbicidas em biótipos destas espécies. Adoção de práticas culturais diversificadas, integradas ao controle químico, pode minimizar os efeitos negativos provocados por buva e, também, prevenir casos de resistência.

Palavras-chave: plantas daninhas, caracterização botânica, interferência, manejo integrado, resistência aos herbicidas,.

\section{ABSTRACT}

Conyza bonariensis (L.) Cronquist and Conyza canadensis (L.) Cronquist are two weed species belonging to Asteraceae family. Frequently, they occur in orchards, vineyards, and in other crops, such as corn, soybean, and cotton and, also, in forage crops and pastures, as well as in fallow areas. This literature review has as objectives to describe and discuss botanical, biological, and ecopysiological characteristics of Conyza species that may facilitate adoption of strategies for their management in crops or to limit their establishment. Conyza canadensis is an annual or biennial species, native of North America; whereas, C. bonariensis is an annual species, native of South America. Spreading of both species occurs by seeds, which are easily dispersed through wind and water. Seeds do not present dormancy and can germinate promptly under favorable conditions of temperature and humidity. In various countries, including Brazil, Conyza biotypes resistant to herbicides were found. Adoption of diversified cultural practices, integrated to were found chemical control, may minimize the negative effects of Conyza, as well as, prevent cases of resistance.

Key words: weeds, botanical characteristics, interference, integrated management, herbicide resistance.

\section{INTRODUÇÃO}

O gênero Conyza inclui, aproximadamente, 50 espécies, as quais se distribuem em quase todo o mundo (KISSMANN \& GROTH, 1999). As espécies que mais se destacam, por seu caráter negativo, são Conyza bonariensis e Conyza canadensis. A primeira espécie é nativa da América do Sul e ocorre de forma abundante na Argentina, no Uruguai, no Paraguai e no Brasil. Neste, sua presença é mais intensa nas regiões Sul, Sudeste e Centro-Oeste. Ela também está presente na Colômbia e na Venezuela, onde infesta lavouras de café (KISSMANN \& GROTH, 1999). Conyza canadensis, porém, é nativa da América do Norte (FRANKTON \& MULLIGAN, 1987), sendo uma das

IPrograma de Pós-graduação em Fitotecnia, Faculdade de Agronomia, Universidade Federal do Rio Grande do Sul (UFRGS), Porto Alegre, RS, Brasil. E-mail: calazaroto@yahoo.com.br. Autor para correspondência.

IIDepartamento de Plantas de Lavoura, Faculdade de Agronomia, UFRGS, Porto Alegre, RS, Brasil. 
espécies mais amplamente distribuídas no mundo (THEBAUD \& ABBOTT, 1995). É uma espécie cosmopolita, sendo mais encontrada em zonas temperadas do hemisfério norte (HOLM et al., 1997) e regiões subtropicais do hemisfério sul, mas é pouco freqüente em regiões tropicais (KISSMANN \& GROTH, 1999). A espécie está presente em quase todas as regiões do Canadá (ROULEAU \& LAMOUREUX, 1992), Estados Unidos (USDA, 1970), oeste da Europa e Planície Mediterrânea (THEBAUD \& ABBOTT, 1995), Austrália e Japão (HOLM et al. 1997). No Brasil, sua presença é significativa em campos nativos e em lavouras, especialmente da região Sul (KISSMANN \& GROTH, 1999).

As espécies $\boldsymbol{C}$. canadensis e $\boldsymbol{C}$. bonariensis, conhecidas popularmente por "buvas", destacam-se por infestarem áreas abandonadas (terrenos baldios $\mathrm{e}$ margens de estradas), pastagens, culturas perenes (citros e café) e lavouras anuais (algodão, milho, soja e trigo) (THEBAUD \& ABBOTT, 1995). Em termos mundiais, estas espécies daninhas infestam mais de 40 culturas (HOLM et al., 1997). Relatou-se que $\boldsymbol{C}$. canadensis, na densidade de 150 plantas $\mathrm{m}^{-2}$, reduziu em $83 \%$ a produtividade de soja cultivada em semeadura direta (BRUCE \& KELLS, 1990). Em beterrabaaçucareira, $\boldsymbol{C}$. canadensis diminuiu a produtividade em $64 \%$ na média de dois anos e, também, inibiu o desenvolvimento de ramos novos em videira na ordem de 28\% (HOLM et al.,1997). Em videira, a ocorrência de Conyza spp. dá-se, principalmente, como plantas daninhas anuais de inverno. Em cenoura e cebola, por outro lado, elas ocorrem como anuais de verão, após o cultivo de inverno. Em cenoura, seus efeitos na eficiência de colheita são mais prejudiciais do que na produtividade da cultura (LEROUX et al. 1996), tendo em vista que os caules e os ramos secos de buva interferem na colheita mecânica de cenoura, mesmo em densidades baixas (como uma planta $\mathrm{m}^{-2}$ ).

Devido à dificuldade de controlar estas espécies, especialmente através do método químico, e devido ao aparecimento de populações de biótipos resistentes aos herbicidas, as práticas de manejo de buva requerem a combinação de múltiplas ações, como: aumento da intensidade de manejo do solo, uso rotineiro da rotação de culturas e adoção de técnicas culturais apropriadas. Diante disso, esta revisão tem por objetivo descrever e discutir as características biológicas e ecofisiológicas das espécies $\boldsymbol{C}$. canadensis e $\boldsymbol{C}$. bonariensis que favorecem sua competição com as culturas pelos recursos do meio ou que possam ser usadas para limitar o estabelecimento e a expansão destas plantas daninhas, especialmente em soja.

\section{DESENVOLVIMENTO}

Em seqüência, desenvolve-se o tema proposto, abordando-se-o sob três aspectos: caracterização das espécies, ecofisiologia de buva e resistência aos herbicidas.

\section{Caracterização das espécies}

No Brasil, é freqüente a ocorrência de ambas as espécies de buva associadas, as quais apresentam adaptabilidade ecológica em sistemas conservacionistas, como semeadura direta e cultivo mínimo de solo. No entanto, é comum haver confusão na diferenciação das espécies. A identificação correta das mesmas é importante para que se possa escolher apropriadamente a melhor estratégia de controle, diminuir a seleção de biótipos resistentes através do uso repetitivo de herbicidas detentores do mesmo mecanismo de ação e identificar o mecanismo de resistência que está envolvido em cada espécie. Assim, na tabela 1 relacionam-se diferenças morfológicas entre as espécies $\boldsymbol{C}$. bonariensis e $\boldsymbol{C}$. canadensis que podem contribuir para as diferenciar corretamente. Destacase que $\boldsymbol{C}$. bonariensis apresenta folhas de margens inteiras (não-denteadas) e presença de ramos laterais que ultrapassam a inflorescência. Por sua vez, $\boldsymbol{C}$. canadensis apresenta ampla panícula terminal no ramo principal e as margens das folhas são finamente denticuladas.

\section{Ecofisiologia de buva}

Ambas as espécies são ruderais de sucessão primária que se estabelecem em áreas perturbadas (TREMMEL \& PETERSON, 1983), inclusive em lavouras, particularmente nos períodos de entressafra e em áreas onde é praticado o manejo reduzido do solo. C. canadensis, por exemplo, representou $11 \%$ da vegetação de plantas sucessoras durante o primeiro ano após o corte de uma floresta cultivada (TREMMEL \& PETERSON, 1983). Plantas de C. canadensis são relativamente abundantes e a altura da inflorescência dos indivíduos decresce notadamente nos dois anos que seguem seu aparecimento. TREMMEL \& PETERSON (1983) atribuíram tal declínio à competição exercida por outras espécies da sucessão. Foi referido haver atividade alelopática de $\boldsymbol{C}$. canadensis, a qual foi atribuída à presença de poliacetilenos, exsudados principalmente pelas raízes (WEAVER, 2001).

Conyza canadensis é encontrada, freqüentemente, em populações muito densas. YODA et al. (1963) constataram que, em densidade superior a 1000 plantas $\mathrm{m}^{-2}$, a mortalidade de plântulas seguia a lei da potência de $3 / 2$. Contudo, o tamanho da população 
Tabela 1 - Caracterização morfológica de espécies de buva (Conyza bonariensis e Conyza canadensis).

\begin{tabular}{|c|c|c|}
\hline Característica & C. bonariensis & C. canadensis \\
\hline Sinônimos & $\begin{array}{l}\text { Erigeron bonariensis, C. albida, C. ambigua, C. } \\
\text { bonariensis var. leiotheca, C. bonariensis var. } \\
\text { microcephala, C. floribunda, C. hispida, C. lineares, } \\
\text { C. linifolia, C. plebeyal }\end{array}$ & $\begin{array}{l}\text { Erigeron canadensis, E. pusillus, Leptilon canadense, } \\
\text { Marsea canadensis }\end{array}$ \\
\hline Nomes comuns & $\begin{array}{l}\text { Acatóia, buva, capetiçoba, capiçoba, catiçoba, enxota, } \\
\text { erva-lanceta, margaridinha-do-campo, rabo-de- } \\
\text { foguete, rabo-de-raposa, salpeixinho, voadeira }\end{array}$ & Buva, buva-do-Canadá, voadeira \\
\hline Ciclo & Anual & Anual ou bienal \\
\hline Origem & América do Sul & América do Norte \\
\hline Tipo & Herbácea & Herbácea \\
\hline Porte & Ereto & Ereto \\
\hline Altura & Até $2 \mathrm{~m}$ & Até $2,5 \mathrm{~m}$ \\
\hline Raiz & Pivotante & Pivotante \\
\hline \multicolumn{3}{|l|}{ Caule } \\
\hline Formato & Cilíndrico & Cilíndrico, glabro ou com pêlos \\
\hline Diâmetro & Até $15 \mathrm{~mm}$ & - \\
\hline Constituição & Sublenhoso na base & Lenhoso \\
\hline Ramificações & $\begin{array}{l}\text { Na base, em baixa densidade e no ápice, em alta } \\
\text { densidade }\end{array}$ & Intensa, apenas na parte superior \\
\hline Ramos & Elevados, ultrapassando o topo do caule & Não ultrapassam o topo do caule \\
\hline Enfolhamento & Intenso em toda extensão & Intenso em toda extensão \\
\hline \multicolumn{3}{|l|}{ Folhas } \\
\hline Formato & Simples, alternas, sésseis, oblanceoladas ou lanceoladas & Isoladas, simples, sésseis, de formato linear-lanceoladas \\
\hline Comprimento & $6-12 \mathrm{~cm}$ & Até $15 \mathrm{~cm}$ \\
\hline Largura & $1,5-2,5 \mathrm{~cm}$ & $1,5 \mathrm{~cm}$ \\
\hline Margens & Não-denteadas & Finamente denteadas \\
\hline \multicolumn{3}{|l|}{ Inflorescência } \\
\hline Tipo & $\begin{array}{l}\text { Panículas formadas por ramos ascendentes na parte } \\
\text { superior do caule e ramos }\end{array}$ & $\begin{array}{l}\text { Ocorre na parte superior da planta onde surge uma } \\
\text { panícula ereta, muito ramificada }\end{array}$ \\
\hline Flores & Capítulos isolados, pedicelados & Capítulos pedicelados \\
\hline \multicolumn{3}{|l|}{ Aquênios } \\
\hline Formato & $\begin{array}{l}\text { Obcônico-comprimidos, retos ou levemente curvados } \\
\text { longitudinalmente }\end{array}$ & $\begin{array}{l}\text { Subcilíndricos, com ápice truncado, pouco mais largos } \\
\text { acima do meio, atenuados para a base }\end{array}$ \\
\hline Comprimento & $1-1,3 \mathrm{~mm}$ & $1,3 \mathrm{~mm}$ \\
\hline Largura & $0,3-0,4 \mathrm{~mm}$ & $0,3 \mathrm{~mm}$ \\
\hline Papus & 10-25 pêlos, com $3-4 \mathrm{~mm}$ de comprimento & $10-25$ pêlos, até 3 vezes o comprimento do aquênio \\
\hline \multicolumn{3}{|l|}{ Plântulas } \\
\hline $\begin{array}{l}\text { Folhas } \\
\text { cotiledonares }\end{array}$ & Ovaladas, de base atenuada e ápice arredondado & $\begin{array}{l}\text { Ovaladas, de base abruptamente atenuada e ápice } \\
\text { arredondado, glabas }\end{array}$ \\
\hline $\begin{array}{l}\text { Hipocótilo } \\
\text { epicótilo }\end{array}$ & Muito curtos & $\begin{array}{l}\text { Imperceptíveis, de modo que se forma sobre o solo uma } \\
\text { roseta para, mais tarde, desenvolver-se o caule }\end{array}$ \\
\hline
\end{tabular}

Adaptado de KISSMANN \& GROTH (1999) e LORENZI (2000, 2006).

desta espécie é regulado pela plasticidade do fenótipo e não propriamente pela mortalidade de plântulas (PALMBLAD, 1968). Com o aumento da densidade, o número de plantas que floresce, o tamanho individual da planta e o número de sementes por planta decrescem, mas a produção global de sementes por unidade de área permanece praticamente constante.

As duas espécies de Conyza são autocompatíveis e, aparentemente, não são polinizadas por insetos, sugerindo a ocorrência de autogamia ou polinização pelo vento (THEBAUD et al., 1996). Conyza canadensis é autocompatível (MULLIGAN \& FINDLAY, 1970); o pólen é liberado antes que os capítulos abram inteiramente, sugerindo autopolinização, embora os insetos visitem as flores abertas (SMISEK, 1995). Ao utilizar plantas resistentes ao herbicida paraquat como marcadoras, SMISEK (1995) constatou que o nível de autocruzamento dentro de uma população de C. canadensis foi de 4\%, aproximadamente (variando de 1,2 a 14,5\%). Também foi relatado ocorrer hibridização entre as espécies $\boldsymbol{C}$. canadensis e outras do gênero Conyza, principalmente 
C. sumatrensis e C. bonariensis, pois estas geralmente crescem em populações associadas e ocorrem de forma freqüente (THEBAUD \& ABBOTT, 1995). Porém, $\boldsymbol{C}$. canadensis é diplóide, com número de cromossomos $2 \mathrm{n}=18$, enquanto as outras espécies são poliplóides (THEBAUD \& ABBOTT, 1995).

A maturação das sementes ocorre três semanas após a fertilização. O peso médio da semente (sem o papus) é de $0,072 \mathrm{mg}$, sendo $15 \%$ representado pela casca e $85 \%$ pelo embrião (FENNER, 1983). O número médio de sementes por capítulo em $\boldsymbol{C}$. canadensis varia de 60 a 70 (SMISEK, 1995; THEBAUD \& ABBOUT, 1995), enquanto em C. bonariensis situase entre 190 e 550 sementes, com média de 400 sementes por capítulo (WU \& WALKER, 2006). O número de capítulos por planta e, conseqüentemente, a produção total de sementes é proporcional à altura do caule (REGEHR \& BAZZAZ, 1979; SMISEK, 1995). Por exemplo, uma planta com $40 \mathrm{~cm}$ de altura produziu cerca de 2000 sementes (aquênios), enquanto uma com 1,5m produziu $230 \mathrm{mil}$ sementes, aproximadamente. Entretanto, verificou-se que $\boldsymbol{C}$. canadensis, numa densidade de 10 plantas $\mathrm{m}^{-2}$, em área sem manejo do solo, produziu cerca de 200 mil sementes por planta (BHOWMIK \& BEKECH, 1993) e que, aproximadamente, $80 \%$ delas germinaram próximo à planta mãe (LOUX et al., 2006). Em outro trabalho, uma planta de $\boldsymbol{C}$. bonariensis produziu, em média, $110 \mathrm{mil}$ aquênios (WU \& WALKER, 2006). Relatou-se que plantas mais altas de $\boldsymbol{C}$. canadensis produzem mais sementes; porém, o vigor reprodutivo (número de sementes por grama de matéria seca) diminui com a altura da planta (REGEHR \& BAZZAZ, 1979).

A propagação de $\boldsymbol{C}$. canadensis e $\boldsymbol{C}$. bonariensis dá-se somente através de sementes. Assim, ocorrem adaptações nos aquênios para facilitar a dispersão das sementes através do vento, as quais são formadas por estruturas chamadas de papus (ANDERSEN, 1993). Estes medem, no mínimo, duas vezes o tamanho da semente, e a altura das plantas ajuda para que a semente paire no ar por um longo período de tempo (REGEHR \& BAZZAZ, 1979). Por exemplo, sementes de $C$. canadensis podem se dispersar pelo vento em distância superior a $100 \mathrm{~m}$ (DAUER et al., 2006). Por outro lado, a distribuição das sementes de C. canadensis em uma lavoura de milho totalizou 14.950 sementes $\mathrm{m}^{-2}$ até a distância de $6 \mathrm{~m}$ da planta mãe, enquanto à distância de $122 \mathrm{~m}$ havia 149 sementes $\mathrm{m}^{-2}$, em média (LOUX et al., 2006). No entanto, a dispersão de sementes também ocorre através da água. Grande quantidade de sementes de $\boldsymbol{C}$. canadensis foi encontrada em canais e nas margens de canais de irrigação (KELLY \& BRUNS, 1975). Como se tratam de espécies anuais que se reproduzem apenas por sementes e estas possuem adaptações para facilitar a dispersão, estes processos são determinantes para se obter redução das infestações, eliminando as populações estabelecidas antes do seu florescimento. Isso pode ser conseguido via controle químico ou mecânico (roçada), atentando especialmente para áreas não-cultivadas (terraços, linhas de cercas, beiras de estradas) e durante o pousio de áreas sob cultivo.

As sementes maduras de buva não são dormentes e podem germinar sempre que as condições de temperatura e umidade forem favoráveis (WU \& WALKER, 2006). Em geral, sementes de C. bonariensis e C. canadensis germinam sob temperaturas entre $10 \mathrm{e}$ $25^{\circ} \mathrm{C}$ (ZINZOLKER et al., 1985). Sementes de $\boldsymbol{C}$. canadensis germinam facilmente em temperaturas de dia:noite de $22: 16^{\circ} \mathrm{C}$ (BUHLER \& OWEN, 1997; BUHLER \& HOFFMAN, 1999), mas não germinam quando as temperaturas de dia:noite forem inferiores a $12: 6^{\circ} \mathrm{C}$ (NANDULA et al., 2006). Porém, a temperatura mínima para germinação de sementes de $\boldsymbol{C}$. canadensis foi estimada em $13^{\circ} \mathrm{C}$ por STEINMAUS et al. (2000). Para germinação de sementes de $\boldsymbol{C}$. bonariensis, um estudo realizado na Austrália constatou que a temperatura ótima é $20^{\circ} \mathrm{C}$ (ROLLIN \& TAN, 2006). Isso explica a emergência de plântulas no início do outono e no início da primavera, quando as temperaturas se aproximam a $20^{\circ} \mathrm{C}$. No entanto, as temperaturas mínima e máxima para germinação de $\boldsymbol{C}$. bonariensis foram estimadas em $4,2^{\circ} \mathrm{Ce} 35^{\circ} \mathrm{C}$, respectivamente (ROLLIN \& TAN, 2006).

Alguns autores relataram que a luz pode ser (ROLLIN \& TAN, 2006) ou não ser (GORSKI, 1975) necessária para desencadear a germinação. Porém, a emergência de $\boldsymbol{C}$. canadensis diminuiu $90 \%$ a partir de sementes enterradas a $1 \mathrm{~cm}$ abaixo da superfície do solo, comparativamente a sementes posicionadas na superfície do solo (TREMMEL \& PETERSON, 1983). Resultado similar foi obtido por NANDULA et al. (2006), que não verificaram emergência a partir de sementes enterradas à profundidade maior que $0,5 \mathrm{~cm}$. Todavia, estudo realizado nos EUA mostrou que nenhuma semente de $\boldsymbol{C}$. canadensis germinou em profundidade acima de $6 \mathrm{~cm}$ (BHOWMIK \& BEKECH, 1993). Na Austrália, um estudo indicou que sementes de $\boldsymbol{C}$. bonariensis emergiram somente na faixa de $1-2 \mathrm{~cm}$ abaixo da superfície do solo e que sua viabilidade foi curta (WALKER et al., 2006). Entretanto, sob condições de laboratório, a maioria das sementes de $\boldsymbol{C}$. bonariensis emergiu à profundidade de $0,5 \mathrm{~cm}$, um pequeno número a $1 \mathrm{~cm}$ e nenhuma semente a $2 \mathrm{~cm}$ (ROLLIN \& TAN, 2006).

Com o objetivo de verificar a influência da luz na germinação de sementes de $\boldsymbol{C}$. canadensis, os 
resultados de um ensaio demonstraram que as sementes desta espécie podem germinar no escuro e, também, quando submetidas a períodos intercalados de $13 \mathrm{~h}$ de luz e $11 \mathrm{~h}$ de escuro. Entretanto, a germinação foi maior quando houve período de luz durante o dia (NANDULA et al., 2006). Considerando que as sementes de buva necessitam de luz para germinar, pode-se impedir que o façam durante a estação fria, agregando-se altos níveis de palha de culturas de cobertura à superfície do solo. Este processo, além de impedir, atrasa a germinação, dando tempo para que a cultura se estabeleça e suprima a população tardia de plantas que, eventualmente, venha a emergir. Resultados de pesquisa mostram que a presença de resíduos de culturas de cobertura $\left(6 \mathrm{t} \mathrm{ha} \mathrm{h}^{-1}\right)$ atrasou a germinação de sementes de $\boldsymbol{C}$. canadensis em quatro semanas e reduziu a emergência total de plântulas em 80\% (BHOWMIK \& BEKECH, 1993).

A ampla distribuição geográfica das espécies de buva sugere que elas possuem poucas limitações climáticas. No entanto, a distribuição de $\boldsymbol{C}$. canadensis é rara em zonas tropicais (HOLM et al., 1997). A produção de sementes e o potencial invasor, porém, limitam-se à latitude de $52^{\circ} \mathrm{N}$, próximo do limite norte de sua distribuição no Canadá (ARCHIBOLD, 1981). No entanto, as duas espécies de Conyza toleram bem condições de deficiência hídrica e continuam crescendo e produzindo sementes em condições estressantes para o desenvolvimento de culturas de interesse econômico. Portanto, o uso de irrigação pode representar alternativa importante para melhorar a capacidade competitiva da cultura no processo competitivo com buva.

As espécies de buva preferem solos acidentados, pedregosos e arenosos, tolerando bem a falta de água (HANF, 1983) e, embora também colonizem áreas planas e úmidas, não toleram inundação do solo (SMITH \& MOSS, 1998). Conyza canadensis comumente é mais encontrada em solos pobres e bem drenados (FRANKTON \& MULLIGAN, 1987). As sementes desta espécie germinam sob condições de alta salinidade do solo (NANDULA et al., 2006) e a germinação ocorre em maior nível em solos de $\mathrm{pH}$ neutro para alcalino, comparativamente aos solos ácidos (NANDULA et al., 2006). Portanto, como as espécies de buva se adaptam melhor a determinadas faixas de $\mathrm{pH}$ do solo, a correção deste deve ser realizada de modo que, primeiramente, atenda às necessidades da cultura e, em segundo lugar, não venha favorecer a buva. Assim, a correção do solo não pode ser exagerada, mas equilibrada.

Conyza canadensis comporta-se como uma espécie anual ou bienal, dependendo das condições de ambiente. A maioria dos indivíduos germina no outono e forma uma roseta basal para sobreviver durante o inverno. Embora possa germinar durante todo o ano (REGEHR \& BAZZAZ, 1979; HOLM et al., 1997), a pequena fração da população que emerge na primavera produz sementes, mas morre no verão (WEAVER, 2001). No Canadá, devido à ocorrência de neve no inverno, a maioria das plântulas emerge tardiamente no verão, formando rosetas ao longo do inverno; poucas plântulas emergem na primavera. Quando as inflorescências são emitidas na primavera, as plantas florescem no início do verão e o pico da produção de sementes ocorre de meados ao final do verão(WEAVER, 2001). Conyza bonariensis, porém, é uma espécie de ciclo tipicamente anual, que se reproduz por sementes. A germinação dessas ocorre com maior intensidade no final do outono e no inverno; o ciclo se completa na primavera ou no verão (KISSMANN \& GROTH, 1999). Estudo realizado na Austrália constatou que as plantas podem emergir durante todo o ano, mas o pico de emergência ocorre durante a primavera (WALKER et al., 2006).

O crescimento da planta de buva, em forma de roseta, permite que ela fixe carbono e acumule energia sob baixas temperaturas (REGEHR \& BAZZAZ, 1979). Sob radiação solar elevada, a temperatura das folhas da roseta, freqüentemente, situa-se $10^{\circ} \mathrm{C}$ acima da temperatura do ambiente. A temperatura ótima do ar para a fotossíntese varia de $28^{\circ} \mathrm{C}$ no verão a $15^{\circ} \mathrm{C}$ no inverno. Foi referido que o ponto de compensação luminoso decresceu de $75 \mu \mathrm{mol} \mathrm{m}^{-2} \mathrm{~s}^{-1}$ à temperatura de $25^{\circ} \mathrm{C}$, para apenas $18 \mu \mathrm{mol} \mathrm{m} \mathrm{m}^{-2} \mathrm{~s}^{-1}$ a $5^{\circ} \mathrm{C}$. O tempo de resposta fotossintética das rosetas à irradiância é muito rápido, mesmo em baixas temperaturas (REGEHR \& BAZZAZ, 1979).

Em condição de laboratório, a longevidade das sementes de C. canadensis manteve-se por dois a três anos (HAYASHI, 1979). Contudo, foram encontradas sementes viáveis de $\boldsymbol{C}$. canadensis no banco de sementes numa área de pastagem abandonada após ausência de 20 anos de plantas da espécie (TSUYUZAKI \& KANDA, 1996). Similarmente, $\boldsymbol{C}$. canadensis foi uma importante espécie presente no banco de sementes em uma área agrícola abandonada durante dez anos, período em que ela não fazia parte da vegetação da área (LECK \& LECK, 1998). Entretanto, KELLY \& BRUNS (1975) constataram que, apesar de encontrarem grandes quantidades de sementes em água de irrigação, aquela espécie representou um reduzido componente do banco de sementes em lavouras adjacentes.

Foi relatado que plântulas de $\boldsymbol{C}$. canadensis emergiram na primavera e no verão em densidades 
relativamente altas em cultivos de cebola e cenoura, sendo que o mesmo não ocorre em lavouras de cevada ou em área sem cultivo onde a quantidade de resíduos culturais era alto (LEROUX et al., 1996). Em trabalho desenvolvido nos EUA, a subtração anual de sementes do banco no solo foi cerca de $6,5 \%$, sendo que a maioria delas emergiu no outono (REGEHR \& BAZZAZ, 1979). A emergência que ocorreu no verão compôs de 5 a $32 \%$ da emergência total anual e a sobrevivência de plântulas de C. canadensis no inverno associou-se ao tamanho da roseta basal da planta e ao comprimento da raiz das mesmas (REGEHR \& BAZZAZ, 1979). Plantas que emergem na primavera possuem baixa mortalidade, mas produzem poucas sementes, comparando àquelas que emergem no outono (BUHLER \& OWEN, 1997).

Em áreas sob semeadura direta de soja, onde não foi realizado cultivo durante o inverno ou as culturas foram colhidas antecipadamente, ocorreu intensa infestação de buva, o que requereu controle antes do estabelecimento das culturas de verão (BRUCE \& KELLS, 1990). No Estado de Indiana, EUA, encontraram-se infestações de buva em $63 \%$ das lavouras de soja cultivadas por dois anos seguidos, comparativamente à ocorrência de $51 \%$ em lavouras de soja sem rotação e a $47 \%$ quando houve rotação entre milho e soja (BARNES et al., 2006). A inclusão de cevada no inverno, como cultura de sucessão, reduziu as populações de $\boldsymbol{C}$. canadensis em cebola e cenoura no verão (LEROUX et al., 1996). O uso de rotação de culturas pressupõe, também, a possibilidade de rotacionar herbicidas com diferentes mecanismos de ação, medida fundamental para se obter sucesso no controle e na prevenção de resistência em populações de buva.

Geralmente, as espécies de Conyza não representam problemas em áreas manejadas sob sistema convencional de cultivo (BROWN \& WHITWELL, 1988). Aumento na intensidade do manejo do solo reduz a presença de $\boldsymbol{C}$. canadensis em $50 \%$ ou mais (BUHLER \& OWEN, 1997). Esta espécie foi encontrada em $61 \%$ das lavouras que não receberam preparo do solo, comparado a $24 \%$ onde houve manejo reduzido do solo e a $8 \%$ em lavouras manejadas no sistema convencional (BARNES et al., 2006). Aumento da quantidade de resíduos de culturas atrasaram a emergência de espécies de buva no outono (BUHLER \& OWEN, 1997). Dessa forma, como as espécies não sobrevivem quando o solo é revolvido, este é um ponto que pode ser explorado para limitar as infestações em áreas agrícolas. Caso haja impedimento para se revolver periodicamente o solo e considerando que no sistema de semeadura direta as sementes não são ou são pouco enterradas, pode-se utilizar esta característica para se obter germinação uniforme das populações, as quais poderiam ser eliminadas mecânica (roçada) ou quimicamente (herbicidas) quando surgissem na área.

\section{Resistência aos herbicidas}

Em 1980, pesquisadores japoneses relataram o primeiro caso de resistência de $\boldsymbol{C}$. canadensis a herbicida, quando detectaram biótipo resistente ao paraquat (HEAP, 2006). O mecanismo de resistência ao paraquat consiste no aprisionamento da molécula herbicida no local de sua ligação no cloroplasto e/ou no aumento da atividade de desintoxicação de enzimas, como da superóxido dismutase (YE et al., 2000). A freqüente utilização de herbicidas gerou o aparecimento de biótipos de Conyza resistentes nos anos subseqüentes. Atualmente, seis e treze países, respectivamente, já referiram casos de biótipos de $\boldsymbol{C}$. bonariensis e $\boldsymbol{C}$. canadensis resistentes para herbicidas com diferentes modos de ação, tais como inibidores dos fotossistemas I e II da enzima EPSPS e da enzima ALS (HEAP, 2006).

Biótipos resistentes de C. canadensis ao grupo de compostos inibidores da enzima ALS foram encontrados, primeiramente, nos EUA e na Polônia no início da década de 2000, em lavouras conduzidas sob sistema de semeadura direta e ao longo de beiras de estradas, respectivamente (HEAP, 2006). O primeiro relato de $\boldsymbol{C}$. canadensis resistente ao herbicida glyphosate ocorreu nos EUA em 2001 (VanGESSEL, 2001). Desde então, o problema se ampliou em vários Estados americanos. Biótipos desta espécie, resistentes ao glyphosate, foram encontrados em áreas onde ocorreram as seguintes práticas de manejo: cultivo de soja na mesma área por vários anos consecutivos (até 14 anos), uso apenas de glyphosate para controlar plantas daninhas e reduzido manejo do solo. No Brasil, foram encontradas populações resistentes de $\boldsymbol{C}$. canadensis e C. bonariensis em pomares de citros (MOREIRA et al., 2006) e de $\boldsymbol{C}$. bonariensis em lavouras cultivadas com soja geneticamente modificada, nas quais predominava o uso do herbicida glyphosate (VARGAS et al., 2006).

Conyza canadensis e $\boldsymbol{C}$. bonariensis têmse caracterizado como espécies que apresentam eficiente adaptabilidade ecológica em sistemas conservacionistas, como semeadura direta ou cultivo mínimo de solo. Esses sistemas fazem com que elas sofram pressão de seleção muito grande, pela utilização intensiva do herbicida glyphosate em cultivos de soja em que se utilizam genótipos transgênicos, favorecendo a seleção de biótipos resistentes. A resistência encontrada em biótipos destas espécies 
deve-se à limitada translocação do glyphosate para os pontos de crescimento das plantas (LORRAINECOLWILL et al., 2003; FENG et al., 2004; KOGER \& REDDY, 2005). No entanto, MUELLER et al. (2003) relataram que a resistência de biótipos de Conyza spp. não se dava em função da translocação do herbicida ou da alteração enzimática, pois não houve diferença no acúmulo de shiquimato nas plantas aos dois e quatro dias após a aplicação do glyphosate, comparando-se biótipos resistentes e suscetíveis. Estes autores sugeriram a possibilidade de existir isômeros da enzima 5-enol-piruvil shiquimato fosfato sintase (EPSPS) em plantas resistentes, os quais possuiriam menor afinidade com a molécula de glyphosate, conferindo caráter de resistência às plantas.

Algumas populações de $\boldsymbol{C}$. canadensis já desenvolveram resistência múltipla para herbicidas com diferentes mecanismos de ação. Assim, na Hungria, foram encontradas populações resistentes simultaneamente aos herbicidas paraquat e atrazine (LEHOCZKI et al., 1984). Em Israel e nos EUA foram identificadas populações resistentes aos compostos atrazine e chlorsulfuron, este um inibidor da enzima ALS (HEAP, 2006). Esta resistência agrava sobretudo o controle químico de buva em lavouras, visto que o herbicida atrazine é utilizado amplamente em lavouras de milho e em outras situações, tanto em áreas agrícolas como em áreas não-cultivadas. Dentre as medidas preconizadas para o manejo da resistência de plantas daninhas aos herbicidas, a vigilância constante da lavoura, no sentido de identificar possíveis focos, é essencial e as plantas suspeitas devem ser sistematicamente eliminadas.

\section{CONCLUSÕES}

Várias causas são responsáveis pelo aumento das infestações de espécies de Conyza em áreas agrícolas, especialmente na cultura da soja. Elas incluem, especialmente: não-adoção de rotação de culturas, uso continuado de manejo reduzido do solo, ocorrência de resistência aos herbicidas devido às aplicações contínuas e freqüentes do mesmo produto (como glyphosate, por exemplo), utilização de herbicidas com igual mecanismo de ação, falha em aplicar combinações de herbicidas com mecanismos de ação distintos, atitude de alienação do agricultor quando surgem plantas de buva em áreas não-cultivadas (beiras de estradas, linhas de cerca, terraços) e não-adoção de medidas para controlar as infestações durante períodos de pousio.

A adoção de práticas de manejo diversificadas que visem a posicionar a cultura de interesse em situação competitiva vantajosa em relação às plantas daninhas, constitui-se em alternativa viável para reduzir a utilização de herbicidas. Para isso, é fundamental praticar intensamente o manejo integrado de plantas daninhas, o qual se baseia na adoção de um conjunto de medidas, especialmente culturais, que alteram as relações de competição em favor da espécie cultivada. As mudanças nas relações de competição pelos recursos do ambiente entre a cultura e as plantas daninhas podem ser alcançadas por meio de práticas de manejo adequadas. Por exemplo, espécies de Conyza não se constituem em problemas em áreas conduzidas sob sistema convencional de cultivo, que inclui o preparo mecânico periódico do solo. A presença de resíduos de culturas (palha) atrasa e reduz a emergência de plântulas de ambas as espécies de buva, medida útil em situações onde se pratica semeadura direta. As sementes de buva requerem determinados critérios para germinar, especialmente quanto à temperatura. Desse modo, pode-se evitar a semeadura da cultura na época em que ocorre maior emergência de buva, desde que se respeite a época preferencial recomendada.

Quanto ao uso do manejo integrado de plantas daninhas, não se pode descartar o emprego do controle químico. Não será apenas com práticas culturais que se conseguirá resolver plenamente o problema das infestações de buva, assim como o uso tão somente de herbicidas poderá não viabilizar sua eliminação. A adoção de práticas culturais eficientes e diversificadas pode levar ao menor uso de herbicidas, seja em número de produtos, de aplicações ou mesmo de doses. Contudo, dificilmente poder-se-á prescindir dos herbicidas. O problema da resistência de plantas daninhas não compromete o método químico de controle em si, mas, freqüentemente, advém do uso incorreto que se faz de determinados herbicidas ou da técnica inadequada de sua utilização.

A adoção de práticas culturais corretas e de elevado nível tecnológico de manejo podem minimizar os efeitos negativos provocados pelas espécies do gênero Conyza, diminuindo, desse modo, a dependência em herbicidas e reduzindo os custos da lavoura, mas mantendo elevado o potencial de produtividade de grãos. Atualmente, há uma tendência de se intensificar as pesquisas relacionadas à identificação de práticas culturais que coloquem as culturas de interesse em situação competitiva vantajosa, sem comprometer o potencial produtivo. Esse fato decorre, por um lado, do reconhecimento da importância negativa das espécies daninhas e, por outro, da necessidade de se racionalizar o uso desses agroquímicos.

Ciência Rural, v.38, n.3, mai-jun, 2008. 


\section{REFERÊNCIAS}

ANDERSEN, M.C. Diaspore morphology and seed dispersal in several wind-dispersed Asteraceae. American Journal of Botany, Columbus, v.80, n.5, p.487-492, 1993.

ARCHIBOLD, O.W. Buried viable propagules in native prairie and adjacent agricultural sites in central Saskatchewan. Canadian Journal of Botany, Ottawa, v.59, n.5, p.701706, 1981 .

BARNES, J. et al. Crop rotation and tillage system influence late-season incidence of giant ragweed and horseweed in Indiana soybean. 2004. Capturado em 26 jun. 2006. Online. Disponível na Internet: http:// www.plantmanagementnetwork.org/pub/cm/brief/2004/late/.

BHOWMIK, P.C.; BEKECH, M.M. Horseweed (Conyza canadensis) seed production, emergence, and distribution in no-tillage and conventional tillage corn (Zea mays). Agronomy, New York, v.1, n.1, p.67-71, 1993.

BROWN, S.M.; WHITWELL, T. Influence of tillage on horseweed, Conyza canadensis. Weed Technology, Champaign, v. 2, n.3, p. $269-270,1988$.

BRUCE, J.A.; KELLS, J.J. Horseweed (Conyza canadensis) control in no-tillage soybeans (Glycine max) with preplant and preemergence herbicides. Weed Technology, Champaign, v.4, n.3, p.642-647, 1990.

BUHLER, D.D.; HOFFMAN, M.L. Andersen's guide to practical methods of propagating weeds and other plants. Lawrence: Weed Science Society of America, 1999. 248p.

BUHLER, D.D.; OWEN, M.D.K. Emergence and survival of horseweed (Conyza canadensis). Weed Science, Lawrence, v.45, n.1, p.98-101, 1997

DAUER, J.T. et al. Controlled experiments to predict horseweed (Conyza canadensis) dispersal distances. Weed Science, Lawrence, v.54, n.3, p.484-489, 2006.

FENG, P.C.C. et al. Investigations into glyphosate resistant horseweed (Conyza canadensis): retention, uptake, translocation, and metabolism. Weed Science, Lawrence, v.52, n.4, p.498-505, 2004.

FENNER, M. Relationships between seed weight, ash content and seedling growth in twenty-four species of Compositae. New Phytologist, New York, v.95, n.4, p.697-706, 1983.

FRANKTON, C.; MULligAN, G.A. Weeds of Canada (revised). Toronto: NC, 1987. 217p.

GÓRSKI, T. Germination of seeds in the shadow of plants Physiologia Plantarum, Copenhagen, v.34, n.4, p.342-346, 1975.

HANF, M. The arable weeds of Europe with their seedlings and seeds. Ludwigshafen: BASF Aktiengesellschaft, 1983. 494p.

HAYASHI, I. Secondary succession of herbaceous communities in Japan: seed germination and shade tolerance of seedlings of the dominants. Bulletin Yokohama Phytosociological Society of Japan, Yokohama, v.16, p.407-419, 1979.
HEAP, I. The international survey of herbicide resistant weeds. 2005. Capturado em: 26 jun. 2006. Online. Disponível na Internet: http://www.weedscience.org/in.asp.

HOLM, L.G. et al. World weeds: natural histories and distribution. Toronto: Wiley, 1997. p.226-235.

KELLY, A.; BRUNS, V. Dissemination of weed seeds by irrigation water. Weed Science, Champaign, v.23, n.6, p.486493, 1975

KISSMANN, K.G.; GROTH, D. Plantas infestantes e nocivas. 2.ed. São Bernardo do Campo: Basf., 1999. p.152$156,278-284$.

KOGER, C.H.; REDDY, K.N. Role of absorption and translocation in the mechanism of glyphosate resistance in horseweed (Conyza canadensis). Weed Science, Lawrence, v.53, n.1, p.84-89, 2005

LECK, M.A.; LECK, C.F. A ten-year seed bank study of old field succession in central New Jersey. Journal of the Torrey Botanical Society, Lawrence, v.125, n.1, p.1132, 1998 .

LEHOCZKI, E. et al. Resistance to triazine herbicides in horseweed (Conyza canadensis). Weed Science, Champaign, v.32, n.6, p.669-674, 1984

LEROUX, G.D. et al. Effect of crop rotations on weed control, Bidens cernua and Erigeron canadensis populations, and carrot yields in organic soils. Crop Protection, Oxford, v.15, n.2, p.171-178, 1996.

LORENZI, H. Manual de identificação e controle de plantas daninhas: plantio direto e convencional. 6.ed. Nova Odessa: Instituto Plantarum, 2006. 339p.

LORENZI, H. Plantas daninhas do Brasil: terrestres, aquáticas, parasitas e tóxicas. 3.ed. Nova Odessa: Instituto Plantarum, 2000. p.143-144.

LORRAINE-COLWILL, D.F. et al. Investigations into the mechanism of glyphosate resistance in Lolium rigidum. Pesticide Biochemistry and Physiology, San Diego, v.74, n.2, p.62-72, 2003.

LOUX, M. et al. Biology and management of horseweed. 2004. Capturado em: 26 jun. 2006. Online. Disponível na Internet: http://www.ipm.uiuc.edu/pubs/horseweed.pdf.

MOREIRA, M.S. et al. Resistência de buva (Conyza bonariensis) ao herbicida glyphosate em pomares de citros do Estado de São Paulo. In: CONGRESSO BRASILEIRO DA CIÊNCIA DAS PLANTAS DANINHAS, 25., 2006, Brasília. Resumos... Londrina: SBCPD, 2006. p.554-555.

MUELLER, T.C. et al. Shikimate accumulates in both glyphosate-sensitive and glyphosate-resistant horseweed (Conyza canadensis L. Cronq.). Journal of Agricultural and Food Chemistry, Washington, v.51, n.3, p.680-684, 2003.

MULLIGAN, G.A.; FINDLAY, J.N. Reproductive systems and colonization in Canadian weeds. Canadian Journal of Botany, Ottawa, v.48, n.5, p.859-860, 1970. 
NANDULA, V.K. et al. Factors affecting germination of horseweed (Conyza canadensis). Weed Science, Lawrence, v.54, n.5, p.898-902, 2006.

PALMBLAD, I.G. Competition in experimental populations of weeds with emphasis on the regulation of population size. Ecology, Washington, v.49, n.1, p.26-34, 1968.

REGEHR, D.L.; BAZZAZ, F.A. The population dynamics of Erigeron canadensis, a successional winter annual. Journal of Ecology, Oxford, v.67, n.3, p.923-933, 1979.

ROLLIN, M.J.; TAN, D. Fleabane: first report of glyphosate resistant flax-leaf fleabane from western Darling Downs. 2004. Capturado em: 26 jun. 2006. Online. Disponível na Internet: http://www.weeds.crc.org.au/documents/fleabane_proceedings $\%$ 20_mar_04.pdf.

ROULEAU, E.; LAMOUREUX, G. Atlas of the vascular plants of the island of Newfoundland and of the islands of Saint-Pierre-et-Miquelon. Quebec: Groupe Fleurbec, 1992. $777 \mathrm{p}$.

SMISEK, A.J.J. The evolution of resistance to paraquat in populations of Erigeron canadensis L. 1995. $102 \mathrm{f}$. Dissertação (Mestrado em Biologia-Ecologia) - University of Western Ontario, London, Ontario.

SMITH, M.; MOSS, J.S. An experimental investigation, using stomatal conductance and fluorescence, of the flood sensitivity of Boltonia decurrens and its competitors. Journal of Applied Ecology, Oxford, v.35, n.4, p.553-561, 1998.

STEINMAUS, S.J. et al. Estimation of base temperatures for nine weed species. Journal of Experimental Botany, Oxford, v.51, n.343, p. 275-286, 2000.

THEBAUD, C. et al. Assessing why two introduced Conyza differ in their ability to invade Mediterranean old fields. Ecology, Washington, v.77, n.3, p.791-804, 1996.

THEBAUD, C.; ABBOTT, R.J. Characterization of invasive Conyza species (Asteraceae) in Europe: quantitative trait and isozyme analysis. American Journal of Botany, Columbus, v.82, n.3, p.360-368, 1995.

TREMMEL, C.D.; PETERSON, K.M. Competitive subordination of a piedmont old field successional dominant by an introduced species. American Journal of Botany, Columbus, v.70, n.8, p.1125-1132, 1983.

TSUYUZAKI, S.; KANDA, F. Revegetation patterns and seedbank structure on abandoned pastures in northern Japan. American Journal of Botany, Columbus, v.83, n.11, p.1422$1428,1996$.

USDA - United States Department of Agriculture. Selected weeds of the United States. Washington: Agriculture Research Service, 1970. 463p. (Agriculture Handbook, n.366)

Van GESSEL, M.J. Glyphosate-resistant horseweed from Delaware. Weed Science, Lawrence, v.49, n.6, p.703-705, 2001 .

VARGAS, L. et al. Resistência de Conyza bonariensis ao herbicida glyphosate. In: CONGRESSO BRASILEIRO DA CIÊNCIA DAS PLANTAS DANINHAS, 25., 2006, Brasília. Resumos... Londrina: SBCPD, 2006. p.540.

WALKER, S. Fleabane: summary of discussion and recomendations. 2004. Capturado em: 26 jun. 2006. Online. Disponível na Internet: http://www.weeds.crc.org.au/documents/ fleabane_proceedings\% 20_mar_04.pdf.

WEAVER, S.E. The biology of Canadian weeds; Conyza canadensis. Canadian Journal of Plant Science, Ottawa, v.81, n.4, p.867-875, 2001.

WU, H.; WALKER, S. Fleabane: fleabane biology and control. 2004. Capturado em: 26 jun. 2006. Online. Disponível na Internet: http://www.weeds.crc.org.au/documents/fleabane_ proceedings \% 20_mar_04.pdf.

YE, B. et al. Correlation of glutathione peroxidase to paraquat/ oxidative stress resistance in Conyza determined by direct fluorometric assay. Pesticide Biochemistry and Physiology, San Diego, v.66, n.3, p.182-194, 2000.

YODA, K. et al. Self-thinning in overcrowded pure stands under cultivated and natural conditions. Journal Biology, Osaka, v.14, n.1, p.107-129, 1963.

ZINZOLKER, A. et al. Effects of environmental factors on the germination and flowering of Conyza albida, C. bonariensis and C. canadensis. Phytoparasitica, Jerusalem, v.13, n.3, p.229-230, 1985. 